\title{
Características agronômicas e suas correlações em híbridos de girassol adaptados à segunda safra
}

\author{
Flávio Carlos Dalchiavon (1), Claudio Guilherme Portela de Carvalho(2), Renato Fernando Amabile ${ }^{(3)}$, \\ Vicente de Paulo Campos Godinho( ${ }^{(4)}$, Nilza Patrícia Ramos ${ }^{(5)}$ e Jefferson Luís Anselmo(6)
}

\begin{abstract}
(1)Instituto Federal de Educação, Ciência e Tecnologia de Mato Grosso, Departamento de Agronomia, Rodovia MT 235, Km 12, Zona Rural, Caixa Postal 100, CEP 78360-000 Campo Novo do Parecis, MT, Brasil. E-mail: flavio.dalchiavon@cnp.ifmt.edu.br (2)Embrapa Soja, Caixa Postal 231, CEP 86001-970 Londrina, PR, Brasil. E-mail: portela.carvalho@embrapa.br ${ }^{(3)}$ Embrapa Cerrados, Caixa Postal 8.223, CEP 73310-970 Planaltina, DF, Brasil. E-mail: renato.amabile@embrapa.br ${ }^{(4)}$ Embrapa Rondônia, Caixa Postal 406, CEP 78900-970 Porto Velho, RO, Brasil. E-mail: vicente.godinho@embrapa.br ${ }^{(5)}$ Embrapa Meio Ambiente, Caixa Postal 69, CEP 13820-000 Jaguariúna, SP, Brasil. E-mail: nilza.ramos@embrapa.br ${ }^{(6)}$ Fundação de Apoio à Pesquisa Agropecuária de Chapadão do Sul, Caixa Postal 39, CEP 79560-000, Chapadão do Sul, MS, Brasil. E-mail: jefferson@fundacaochapadao.com.br
\end{abstract}

Resumo - O objetivo deste trabalho foi avaliar as características agronômicas de híbridos de girassol adaptados à segunda safra e determinar as correlações entre elas. Testaram-se 15 híbridos - dois alto oleicos e 13 não alto oleicos (híbridos tradicionais) -, além de um híbrido como testemunha. Um delineamento experimental de blocos ao acaso foi utilizado com quatro repetições, e as semeaduras foram feitas em 2013 e 2014. As características avaliadas foram as seguintes: dias para a maturação fisiológica, altura de planta, produtividade de grãos, teor de óleo e produtividade de óleo. As maiores produtividades de grãos ocorreram em híbridos que não são nem precoces nem de porte mais baixo. A correlação entre produtividade de grãos e produtividade de óleo foi positiva e significativa; no entanto, as correlações entre teor de óleo e essas duas características não foram significativas. Os híbridos de girassol 'Syn 045' e 'Syn 3950A' (alto oleico) se destacaram, na segunda safra, quanto à produtividade de grãos e de óleo. O híbrido 'CF 101' - ciclo precoce - apresenta boa produtividade de grãos e de óleo e, portanto, é a opção adequada para a semeadura tardia na segunda safra. Assim, estão disponíveis híbridos de girassol adaptados e com características adequadas ao cultivo de segunda safra e às demandas do mercado.

Termos para indexação: Helianthus annuus, oleaginosa, óleo, produtividade.

\section{Agronomic traits and their correlations in sunflower hybrids adapted to second crop}

\begin{abstract}
The objective of this work was to evaluate the agronomic traits of sunflower hybrids adapted to second crop and to determine the correlations between them. Fifteen hybrids were tested - two high-oleic and 13 non high-oleic ones (traditional hybrids) -, besides one hybrid used as a check. A randomized complete block experimental design was carried out with four replicates, and sowings were done in 2013 and 2014. The evaluated traits were the following: days to physiological maturity, plant height, grain yield, oil content, and oil yield. The higher grain yields occurred in hybrids that are neither of early cycles nor of shorter stems. The correlation between grain yield and oil yield was positive and significant; however, the correlations between oil content and these two traits were not significant. The 'Syn 045' and 'Syn 3950A' sunflower hybrids (higholeic) stood out, in the second season, both for grain yield and oil yield. The 'CF 101' hybrid - early cycle shows good grain and oil yield, and, therefore, it is an appropriate option for late sowing in the second season. Thus, adapted sunflower hybrids with appropriate traits are available for second season cropping and to meet market demands.
\end{abstract}

Index terms: Helianthus annuus, oilseed, oil, yield.

\section{Introdução}

Os grãos de girassol (Helianthus annuus L.) podem ser utilizados para a extração de óleo de alta qualidade. Este óleo apresenta teores de ácido linoleico entre 55 e $65 \%$ que ajudam a reduzir o colesterol plasmático e, por consequência, diminuem os riscos de doenças cardiovasculares (Nagarathna et al., 2011). Genótipos mutantes (girassol alto oleico) têm sido obtidos com teores de ácido oleico acima de 80\% (Pacureanu-Joita et al., 2005). Além dos benefícios à saúde, como aqueles proporcionados pelo ácido graxo linoleico, o 
óleo rico em ácido graxo oleico apresenta maior grau de estabilidade oxidativa (Nagarathna et al., 2011). No processo de extração, obtém-se também um farelo (coproduto) altamente proteico e usado na produção de ração animal (Silva et al., 2009; Rodrigues et al., 2013).

Além da qualidade do óleo e do farelo, o girassol apresenta ampla adaptabilidade às condições edafoclimáticas do Brasil e é mais tolerante à seca, ao frio e ao calor do que a maioria de outros cultivos agrícolas no país (Castro \& Farias, 2005). Assim, o girassol é uma boa opção de cultivo para a rotação ou sucessão de culturas nos diferentes sistemas de produção, principalmente em segunda safra.

No Brasil, é comum a realização de uma segunda safra com semeadura em fevereiro/março. Embora a área ocupada pela cultura ainda seja pequena (aproximadamente $110 \mathrm{mil} \mathrm{ha,} \mathrm{na} \mathrm{safra} \mathrm{2014/2015),} \mathrm{o}$ girassol é uma das espécies que pode ser semeada nessa época, em razão da ocorrência de condições pluviais (200 a $600 \mathrm{~mm})$ e de temperaturas adequadas (20 a $28^{\circ} \mathrm{C}$ ) ao seu cultivo (Inmet, 2015; Acompanhamento..., 2016).

O sucesso do estabelecimento da cultura do girassol no sistema produtivo brasileiro depende, entre outros fatores, da utilização de genótipos adaptados e com características mais adequadas às regiões de cultivo, que facilitam as práticas culturais, diminuem o risco de perdas de produção e aumentam a rentabilidade do produtor.

No Brasil, a experimentação e a seleção de híbridos de girassol vêm sendo feitas por meio da Rede de Ensaios de Avaliação de Genótipos de Girassol, coordenada pela Embrapa, que conta com a participação de empresas públicas e privadas. A cada ano, novos genótipos são avaliados em condições edafoclimáticas distintas, de forte influência na adaptação da cultura. Nesse sentido, a avaliação de características agronômicas dos híbridos que apresentaram melhor adaptação nos ensaios (Grunvald et al., 2008, 2014a; Porto et al., 2008; Carvalho et al., 2015), em condições edafoclimáticas similares, pode facilitar a escolha do híbrido pelo produtor.

A escolha do híbrido deve ser realizada tendo em vista as condições de cultivo e de modo a satisfazer as demandas de mercado, principalmente quanto à produtividade de grãos e de óleo e quanto à qualidade do óleo. Outras características também são importantes na seleção, como altura de planta e ciclo precoce. O porte baixo é desejável, por facilitar os tratos culturais, como a aplicação de agroquímicos; e a precocidade facilita a adequação da época de semeadura dentro do sistema de produção das regiões de cultivo (Leite et al., 2005).

Em programas de melhoramento genético de uma cultura, o estudo de correlações entre as características agronômicas de plantas, em populações segregantes, possibilita verificar a viabilidade da seleção indireta de proporcionar ganhos genéticos mais rápidos do que a seleção direta para o caráter desejado (Cruz \& Carneiro, 2006; Nogueira et al., 2012). Contudo, quando os genótipos em avaliação são híbridos adaptados, pertencentes a diferentes programas de melhoramento, o estudo de correlações gera informações que resultam em maior ou menor dificuldade de escolha de híbridos com características desejáveis pelo produtor e, por consequência, na eficiência dos programas. Quando o interesse for utilizar esses híbridos como fonte de variabilidade em um programa de melhoramento, o valor da correlação reflete a maior ou menor dificuldade para se desenvolverem novos genótipos com características desejáveis. Assim, se um caráter correlacionar-se negativamente a alguns e positivamente a outros caracteres, deve-se tomar cuidado para, ao selecionar alguns dos caracteres, não provocar mudanças indesejáveis em outros (Cruz \& Carneiro, 2006).

O objetivo deste trabalho foi avaliar características agronômicas de híbridos de girassol, adaptados à segunda safra, e determinar as correlações entre elas.

\section{Material e Métodos}

Avaliaram-se 15 híbridos de girassol e um híbrido testemunha, nos ensaios finais de primeiro ano (EF1A $-1{ }^{\circ}$ ano de avaliação) e de segundo ano (EF2A $-2{ }^{\circ}$ ano de avaliação), pertencentes à Rede de Ensaios de Avaliação de Genótipos de Girassol. Esses híbridos são adaptados ao cultivo de segunda safra e apresentam bons rendimentos de grãos e de óleo (Grunvald et al., 2008, 2014a; Porto et al., 2008; Carvalho et al., 2015).

Os ensaios foram semeados entre fevereiro e março de 2013 e 2014, em delineamento experimental de blocos completos ao acaso, com quatro repetições, em que se avaliaram os híbridos 'ADV 5504', 'Aguará 4', 'Aguará 6', 'BRS 323', 'BRS G42', 'CF 101', 'GNZ Neon', 'Helio 250', 'Helio 251', 'HLA 2012', 'MG 305', 'MG

Pesq. agropec. bras., Brasília, v.51, n.11, p.1806-1812, nov. 2016 DOI: $10.1590 / \mathrm{S} 0100-204 X 2016001100002$ 
360', 'Paraiso 20', 'Syn 045' e 'Syn 3950A'. Os híbridos 'ADV 5504' e 'Syn 3950A' são alto oleicos, e os demais são não alto oleicos (híbridos tradicionais). O híbrido 'M 734' (híbrido tradicional) foi incluído nos ensaios como testemunha, por apresentar alta estabilidade de produtividade de grãos em cultivo de segunda safra (Grunvald et al., 2008, 2014a; Porto et al., 2008; Carvalho et al., 2015).

Cada parcela experimental constituiu-se de quatro fileiras de $6 \mathrm{~m}$ de comprimento, espaçadas em $0,7 \mathrm{ou}$ $0,8 \mathrm{~m}$. Semearam-se três sementes por cova e, aos 10 dias após a emergência (DAE), ao desbaste das plantas, deixou-se apenas uma semente por cova, para uma população de 45 mil plantas $\mathrm{ha}^{-1}$. À colheita, as duas fileiras externas e $0,5 \mathrm{~m}$ de cada extremidade das linhas centrais foram descartadas, tendo-se obtido uma área útil na parcela de 7,0 ou $8,0 \mathrm{~m}^{2}$, conforme o espaçamento adotado. A faixa de espaçamentos adotada ficou dentro do recomendado para a cultura (Leite et al., 2005) e variou, para cada local, em razão do tipo de semeadora disponível e regulada para a cultura principal.

Os tratos culturais como adubação, capina e controle de insetos-praga e doenças foram realizados conforme as recomendações técnicas para a cultura (Leite et al., 2005).

Os EF1A foram conduzidos na segunda safra, em 2013, nos seguintes locais e respectivos espaçamentos entre linhas, época de semeadura e instituições/ empresas responsáveis: Espírito Santo do Pinhal, SP, 0,8 m, 10/04/2013, Embrapa Meio Ambiente; Manduri, SP, 0,8 m, 21/02/2013, Coordenadoria de Assistência Técnica (Cati); Ribeirão Preto, SP, 0,7 m, 15/03/2013, Centro Universitário Moura Lacerda; Anápolis, GO,
0,8 m, 27/02/2013, Agência Goiana de Assistência Técnica, Extensão Rural e Pesquisa Agropecuária; Campo Novo do Parecis, MT, 0,8 m, 10/03/2013, Instituto Federal de Educação, Ciência e Tecnologia de Mato Grosso (IFMT); Vilhena, RO - Ensaio A, 0,8 m, 05/03/2013, Embrapa Rondônia; Vilhena, RO - Ensaio B, 0,8 m, 15/03/2013, Embrapa Rondônia; e Planaltina, DF, 0,8 m, 01/03/2013, Embrapa Cerrados. Os EF2A foram conduzidos no ano de 2014, em: Manduri, SP, 0,8 m, 14/03/2014, Cati; Paraguaçu Paulista, SP, 0,7 m, 25/02/2014, Escola Superior de Agronomia de Paraguaçu Paulista; Uberlândia, MG, 0,7 m, 12/03/2014, Heliagro; Campo Novo do Parecis, MT, 0,8 m, 07/03/2014, IFMT; Chapadão do Sul, MS, $0,7 \mathrm{~m}, 25 / 03 / 2014$, Fundação de Apoio à Pesquisa Agropecuária de Chapadão; Planaltina, DF, 0,8 m, 20/02/2014, Embrapa Cerrados; Vilhena, RO - Ensaio A, 0,8 m, 11/03/2014, Embrapa Rondônia; e VilhenaEnsaio B, 0,8 m, 20/03/2014, Embrapa Rondônia. As coordenadas geográficas e tipos de solo, segundo Santos et al. (2013), estão apresentados na Tabela 1.

As características agronômicas avaliadas em cada local, ano e espaçamento, foram: dias para a maturação fisiológica, quando $90 \%$ das plantas da parcela apresentavam capítulos com brácteas de coloração entre amarelo e castanho (fase $\mathrm{R}_{9}$ ); altura de planta $(\mathrm{cm})$, obtida pela média de 10 plantas amostradas aleatoriamente na área útil, em floração plena (fase $\mathrm{R}_{5.5}$ ), e medida do nível do solo até a inserção do capítulo; produtividade de grãos $\left(\mathrm{kg} \mathrm{ha}^{-1}\right)$, corrigida para a condição de umidade de $11 \%$; teor de óleo (\%),

Tabela 1. Coordenadas geográficas e tipos de solo de plantios de girassol, semeados de fevereiro a março de 2013 e 2014.

\begin{tabular}{|c|c|c|c|c|c|}
\hline \multirow[t]{2}{*}{ Estado } & \multirow[t]{2}{*}{ Cidade / ano de plantio } & \multicolumn{3}{|c|}{ Coordenadas Geográficas } & \multirow[t]{2}{*}{ Tipo de solo } \\
\hline & & Latitude (S) & Longitude (W) & Altitude (m) & \\
\hline \multirow{4}{*}{ São Paulo } & Espírito Santo do Pinhal/2013 & $22^{\circ} 09^{\prime} 59^{\prime \prime}$ & $46^{\circ} 44^{\prime} 07^{\prime \prime}$ & 880 & Argissolo VermelhoAmarelo \\
\hline & Manduri/2013 & $23^{\circ} 00^{\prime} 12^{\prime \prime}$ & $49^{\circ} 19^{\prime} 19^{\prime \prime}$ & 710 & Latossolo Vermelho \\
\hline & Paraguaçu Paulista/2014 & $22^{\circ} 26^{\prime} 06^{\prime \prime}$ & $50^{\circ} 35^{\prime} 38^{\prime \prime}$ & 514 & Latossolo Vermelho distroférrico \\
\hline & Ribeirão Preto/2013 & $21^{\circ} 10^{\prime} 39^{\prime \prime}$ & $47^{\circ} 48^{\prime} 37^{\prime \prime}$ & 546 & Latossolo Vermelho distroférrico \\
\hline Minas Gerais & Uberlândia/2014 & $18^{\circ} 55^{\prime} 07^{\prime \prime}$ & $48^{\circ} 16^{\prime} 38^{\prime \prime}$ & 863 & Latossolo Vermelho-Amarelo \\
\hline Mato Grosso & Campo Novo do Parecis/2013, 2014 & $13^{\circ} 40^{\prime} 37^{\prime \prime}$ & $57^{\circ} 47^{\prime} 30^{\prime \prime}$ & 574 & Latossolo Vermelho distrófico \\
\hline Mato Grosso do Sul & Chapadão do Sul/2014 & $18^{\circ} 41^{\prime} 33^{\prime \prime}$ & $52^{\circ} 40^{\prime} 45^{\prime \prime}$ & 814 & Latossolo Vermelho distrófico \\
\hline Distrito Federal & Planaltina/2014 & $15^{\circ} 35^{\prime} 30^{\prime \prime}$ & $47^{\circ} 42^{\prime} 30^{\prime \prime}$ & 1007 & Latossolo Vermelho \\
\hline Goiás & Anápolis/2013 & $16^{\circ} 19^{\prime} 36^{\prime \prime}$ & $48^{\circ} 57^{\prime} 10^{\prime \prime}$ & 1017 & Latossolo Vermelho \\
\hline$\underline{\text { Rondônia }}$ & Vilhena/ Ensaios A e B $(2013,2014)$ & $12^{\circ} 47^{\prime} 25^{\prime \prime}$ & $60^{\circ} 05^{\prime} 50^{\prime \prime}$ & 612 & Latossolo Vermelho-Amarelo \\
\hline
\end{tabular}


predito por espectroscopia (Grunvald et al., 2014b); e produtividade de óleo $\left(\mathrm{kg} \mathrm{ha}^{-1}\right)$.

Análises de variância foram realizadas para as características aferidas em cada local, ano e espaçamento. Como variaram os locais de teste e espaçamentos entre EF1A e EF2A, realizou-se a análise conjunta de 16 ambientes (combinação de local, ano e espaçamento), a 1 e $5 \%$ de probabilidade. Para tanto, verificou-se, para cada característica, a existência de homogeneidade das variâncias residuais, obtidas nas análises individuais de ambiente sempre que a razão entre o maior e o menor quadrado médio residual foi inferior a sete (Pimentel-Gomes, 2009). Nas análises, o genótipo foi considerado efeito fixo, e o ambiente, efeito aleatório. Aplicou-se também o teste de Duncan, a 5\% de probabilidade, além da análise de correlação de Pearson entre as variáveis, a 1 e $5 \%$ de probabilidade. As análises estatísticas foram realizadas com auxílio do programa estatístico Genes (Cruz, 2013).

\section{Resultados e Discussão}

Os coeficientes de variação (CV) das análises de variância conjuntas, para as características agronômicas dos híbridos de girassol, foram classificados como baixos ou médios (Tabela 2), de acordo com a classificação proposta por Carvalho et al.
(2003) e Pimentel-Gomes (2009), e foram similares aos obtidos em outros trabalhos correlatos (Backes et al., 2008; Grunvald et al., 2008, 2014a; Porto et al., 2008; Silva et al., 2009; Nobre et al., 2012; Carvalho et al., 2015).

Para todas as características agronômicas avaliadas, houve diferenças significativas entre os híbridos, entre ambientes e de interação genótipo-ambiente. Apesar de observada a interação genótipo-ambiente, testes de médias dos ambientes foram realizados para diferenciar os híbridos, pois, o maior interesse deste trabalho foi avaliar as suas características agronômicas na segunda safra e não para cada ambiente.

A maturação fisiológica dos híbridos, semeados na segunda safra de 2013 e 2014, foi de 94 dias, em média, com variação de 87 a 99 dias (Tabela 2). Backes et al. (2008) analisaram o comportamento de genótipos de girassol, no Município de Papanduva (Planalto Norte Catarinense), e relataram que o genótipo 'M 734' apresentou 105 dias entre a emergência e a maturação fisiológica, valor bem superior ao obtido no presente trabalho (95 dias), provavelmente em razão da influência ambiental sobre a expressão dessa característica (Carvalho et al., 2012; Nobre et al., 2012), uma vez que a região em que foi desenvolvido o

Tabela 2. Características agronômicas de híbridos de girassol cultivados em segunda safra, nos anos de 2013 e 2014, com as médias de 16 locais de plantio ${ }^{(1)}$.

\begin{tabular}{|c|c|c|c|c|c|}
\hline Genótipo & $\begin{array}{l}\text { Maturação fisiológica } \\
\text { (dias) }\end{array}$ & $\begin{array}{l}\text { Altura de planta } \\
(\mathrm{cm})\end{array}$ & $\begin{array}{l}\text { Produtividade de grãos } \\
\qquad\left(\mathrm{kg} \mathrm{ha}^{-1}\right)\end{array}$ & $\begin{array}{c}\text { Teor de óleo } \\
(\%)\end{array}$ & $\begin{array}{c}\text { Produtividade de óleo } \\
\left(\mathrm{kg} \mathrm{ha}^{-1}\right)\end{array}$ \\
\hline 'Syn 045' & $97 \mathrm{ab}$ & $188 b$ & $2259 a$ & $43,4 d$ & $974 a$ \\
\hline 'GNZ Neon' & $99 \mathrm{a}$ & $199 a$ & $2215 \mathrm{ab}$ & $39,1 \mathrm{f}$ & $869 \mathrm{bcd}$ \\
\hline 'Syn 3950A' (alto oleico) & $94 b c$ & $178 \mathrm{c}$ & $2159 \mathrm{abc}$ & $46,3 b$ & $1000 \mathrm{a}$ \\
\hline 'M 734'(2) & $95 \mathrm{bc}$ & $174 \mathrm{~cd}$ & $2077 \mathrm{abcd}$ & $38,9 f$ & $824 \mathrm{~cd}$ \\
\hline 'Helio 251' & $91 \mathrm{~cd}$ & $181 \mathrm{c}$ & $2077 \mathrm{abcd}$ & $40,8 \mathrm{e}$ & $861 \mathrm{bcd}$ \\
\hline 'CF 101' & $88 \mathrm{f}$ & $152 \mathrm{f}$ & 2021bcde & $44,9 \mathrm{c}$ & $929 a b$ \\
\hline 'MG 360' & $93 \mathrm{bc}$ & $159 \mathrm{e}$ & 2018bcde & $48,0 \mathrm{a}$ & $1012 \mathrm{a}$ \\
\hline 'Paraíso 20' & $97 \mathrm{ab}$ & $194 \mathrm{ab}$ & 1985 cde & $44,5 \mathrm{c}$ & $886 b c$ \\
\hline 'BRS 323' & $87 f$ & $155 \mathrm{ef}$ & 1944def & $43,1 \mathrm{~d}$ & $838 b c d$ \\
\hline 'Aguará 06' & $96 \mathrm{ab}$ & $175 \mathrm{~cd}$ & 1943def & $42,6 \mathrm{~d}$ & $834 \mathrm{bcd}$ \\
\hline Aguará 04 & $92 \mathrm{~cd}$ & $169 d$ & $1887 \mathrm{defg}$ & $44,7 \mathrm{c}$ & $853 b c d$ \\
\hline 'MG 305' & $96 a b$ & $179 \mathrm{c}$ & $1883 \mathrm{defg}$ & $44,7 \mathrm{c}$ & $821 \mathrm{~cd}$ \\
\hline 'Helio 250' & 91de & $159 \mathrm{e}$ & 1817 efgh & $44,4 \mathrm{c}$ & $808 \mathrm{~cd}$ \\
\hline 'ADV 5504' (alto oleico) & $88 \mathrm{f}$ & $151 \mathrm{f}$ & 1759 fgh & $46,4 b$ & $850 \mathrm{bcd}$ \\
\hline 'HLA 2012' & $97 \mathrm{ab}$ & $179 \mathrm{c}$ & $1696 \mathrm{gh}$ & $44,9 \mathrm{c}$ & $770 \mathrm{de}$ \\
\hline 'BRS G42' & $89 \mathrm{ef}$ & $144 \mathrm{~g}$ & $1681 \mathrm{~h}$ & $41,0 \mathrm{e}$ & $695 \mathrm{e}$ \\
\hline Média Geral & 94 & 170 & 1962 & 43,6 & 861 \\
\hline Coeficiente de variação (\%) & 3,9 & 5,8 & 13,5 & 4,6 & 13,8 \\
\hline
\end{tabular}

${ }^{(1)}$ Médias seguidas de letras iguais, nas colunas, não diferem pelo teste de Duncan, a 5\% de probabilidade. ${ }^{(2)}$ Testemunha do ensaio. 
trabalho apresentava temperaturas mais baixas do que os locais aqui avaliados.

A depender da época de plantio, pode haver limitações hídricas ao adequado desenvolvimento da cultura em segunda safra. Quando há limitação, a precocidade é desejável, para que haja menor interferência do ambiente sobre o enchimento de grãos, o que permite uma produtividade satisfatória, tanto de grãos quanto de óleo (Carvalho et al., 2012; Nobre et al., 2012). Nos ensaios, os genótipos mais precoces foram 'BRS 323', 'CF 101', 'ADV 5504' e 'BRS G42', com maturação fisiológica inferior a 90 dias. Por serem os mais precoces e ficarem menos tempo em campo, esses híbridos estão menos sujeitos à incidência de insetos-praga, doenças e deficit hídrico, em comparação aos híbridos mais tardios. Isto pode reduzir o risco de perdas de produção e qualidade dos grãos, caso o controle desses agentes não seja eficientemente realizado.

Os híbridos apresentaram altura média de planta de $170 \mathrm{~cm}$, com variação de 144 a $199 \mathrm{~cm}$ (Tabela 2). Houve tendência de os genótipos com menor altura de planta serem também os mais precoces $(\mathrm{r}=0,91)$ (Tabela 3$)$, o que também foi verificado por Silva et al. (2009). Além de facilitar os tratos culturais, plantas de menor porte tendem a quebrar menos quando em presença de intempéries, minimizam as perdas na colheita mecanizada e proporcionam maior sustentação ao capítulo (Leite et al., 2005).

No que tange à produtividade de grãos, a média dos ensaios foi de $1.962 \mathrm{~kg} \mathrm{ha}^{-1}$, com valores entre 1.681 e $2.259 \mathrm{~kg} \mathrm{ha}^{-1}$ (Tabela 2). De acordo com o Acompanhamento... (2016), a produtividade nacional média de grãos de girassol, na safra 2014/2015, foi de $1.374 \mathrm{~kg} \mathrm{ha}^{-1}$. Assim, tanto a média geral quanto a menor produtividade de grãos, observadas no presente trabalho, foram superiores às médias observadas no País.

Tabela 3. Estimativas de correlações de Pearson entre características agronômicas de híbridos de girassol semeados em segunda safra, nos anos de 2013 e 2014, em 16 locais de plantio.

\begin{tabular}{|c|c|c|c|c|}
\hline Característica & $\begin{array}{c}\text { Altura de } \\
\text { planta }\end{array}$ & $\begin{array}{l}\text { Produtividade } \\
\text { de grãos }\end{array}$ & $\begin{array}{l}\text { Teor de } \\
\text { óleo }\end{array}$ & $\begin{array}{c}\text { Produtividade } \\
\text { de óleo }\end{array}$ \\
\hline Maturação fisiológica & $0,91 * *$ & 0,49 & 0,22 & 0,21 \\
\hline Altura de planta & & $0,61 *$ & 0,29 & 0,29 \\
\hline Produtividade de grãos & & & 0,24 & $0,74 * *$ \\
\hline Teor de óleo & & & & 0,43 \\
\hline
\end{tabular}

*, **Significativo a 5 e $1 \%$ de probabilidade, respectivamente.

Pesq. agropec. bras., Brasília, v.51, n.11, p.1806-1812, nov. 2016 DOI: 10.1590/S0100-204X2016001100002
Todavia, os resultados aqui obtidos estão condizentes com os valores obtidos em outros ensaios com girassol conduzidos em segunda safra (Grunvald et al., 2008, 2014a; Porto et al., 2008; Carvalho et al., 2015).

Os genótipos de maior produtividade de grãos foram 'Syn 045', 'GNZ Neon', 'Syn 3950A', 'M 734' (testemunha) e 'Helio 251' (Tabela 2), e nenhum deles apresentou porte baixo nem ciclo precoce. Híbridos com maior produtividade de grãos tenderam a ter maior altura de planta $(\mathrm{r}=0,61)$, conforme verificado em 'GNZ Neon' e 'Syn 045' (Tabelas 2 e 3). No entanto, a correlação entre produtividade de grãos e maturação fisiológica não foi significativa, o que contraria Castro \& Farias (2005), que relataram que genótipos de ciclo mais tardio apresentaram um período de tempo maior para o enchimento dos grãos e tenderam à maior produtividade. Os resultados do presente trabalho podem estar refletindo o esforço dos programas de melhoramento genético de girassol para a obtenção de genótipos produtivos e precoces.

Embora não tenha sido a mais alta, a produtividade de grãos pelo híbrido 'CF 101' foi boa (acima de $2.000 \mathrm{~kg} \mathrm{ha}^{-1}$ ) e a de óleo também, ambas associadas à precocidade (maturação fisiológica com menos de 90 dias). Quando há limitações hídricas ao perfeito desenvolvimento da cultura - como costuma ocorrer em épocas de semeadura tardia na segunda safra - a adoção de um genótipo com essas características pode ser também interessante para melhor adequação ao período de cultivo de segunda safra.

Atualmente, algumas indústrias processadoras de grãos de girassol bonificam lotes com teores de óleo acima de $40 \%$, depreciando aqueles com índice inferior. Nos anos agrícolas 2013 e 2014, a média do teor de óleo dos híbridos foi de 43,6\%, com variação de 39,1 a 48,0\% (Tabela 2). Dos genótipos avaliados, somente 'M 734' (testemunha) e 'GNZ Neon' apresentaram teores de óleo inferiores ao limite estabelecido por essas indústrias para a não depreciação do lote. Apenas 'Syn 3950A' mostrou simultaneamente alto teor de óleo e maior produtividade de grãos.

Ao relacionar os dados de produtividade de grãos com os de teor de óleo, é possível obter informações sobre a produtividade de óleo que é importante para a indústria que beneficia a produção de girassol. A produtividade média de óleo dos híbridos foi de $861 \mathrm{~kg} \mathrm{ha}^{-1}$, com variação de 692 a $1.012 \mathrm{~kg} \mathrm{ha}^{-1}$ 
(Tabela 2). Os híbridos de maior produtividade de óleo foram 'MG 360', 'Syn 3950A', 'Syn 045' e 'CF 101'.

A correlação entre produtividade de grãos e produtividade deóleo foi positiva e significativa $(\mathrm{r}=0,74)$ (Tabela 3). Porém, o incremento da produtividade de óleo de um híbrido não pode ser atribuído ao aumento do teor de óleo, pois, as correlações do teor de óleo com produtividade de grãos e produtividade de óleo foram não significativas. $\mathrm{O}$ valor dessas correlações reflete uma dificuldade dos programas de melhoramento, que poderá ocorrer quando se desenvolverem novos genótipos por meio de seleção multivariada com estas características e utilizarem esse conjunto de híbridos como fonte de variabilidade.

Dos híbridos de maior produtividade de grãos, 'Syn 045' e 'Syn 3950A' (alto oleico) tiveram também as maiores produtividades de óleo (Tabela 2). Apesar de não terem se destacado quanto à produtividade de grãos, 'MG 360' e 'CF 101' apresentaram produtividade de óleo superior à dos outros híbridos. Além da boa produtividade de grãos, ciclo precoce e porte baixo, o híbrido 'CF 101' mostrou alta produtividade de óleo. Quando um genótipo for superior em apenas um dos componentes de rendimento avaliados, a escolha do melhor híbrido pelo produtor deve se basear na política vigente de comercialização das indústrias processadoras de girassol (bonificação com teores de óleo acima de 40\%) (Grunvald et al., 2008, 2014a; Porto et al., 2008; Carvalho et al., 2015). Quanto maior for a bonificação do teor de óleo acima do limite estabelecido por uma empresa, maior será a preferência por híbridos com maior produtividade de óleo associada ao maior teor de óleo.

De acordo com os resultados, foi possível identificar híbridos com alto potencial produtivo de grãos e de óleo, associado à qualidade do óleo, para o cultivo de segunda safra no Brasil, o que satisfaz as diferentes demandas de mercado. Além disso, foi possível selecionar híbridos produtivos, precoces e de porte mais baixo, características estas que são adequadas para este cultivo.

\section{Conclusões}

1. Os híbridos de girassol tradicional 'Syn 045', 'CF 101' (de porte baixo e ciclo precoce) e o 'Syn 3950A' (alto oleico) apresentam boa produtividade de grãos e de óleo em segunda safra.
2. A correlação entre produtividade de grãos e produtividade de óleo é positiva e significativa.

\section{Agradecimentos}

Aos pesquisadores e às instituições participantes da Rede de Ensaios de Avaliação de Genótipos de Girassol, cujos dados experimentais foram usados para a elaboração deste artigo.

\section{Referências}

ACOMPANHAMENTO DA SAFRA BRASILEIRA [DE] GRÃOS: safra 2015/2016: sexto levantamento, Brasília, v.3, n.6, mar. 2016. 135p. Disponível em: <http://www.conab.gov. br/OlalaCMS/uploads/arquivos/16_03_11_15_20_36_boletim graos_marco_2016.pdf $>$. Acesso em: 14 mar. 2016.

BACKES, R.L.; SOUZA, A.M. de; BALBINOT JUNIOR, A.A.; GALlOTTI, G.J.M.; BAVARESCO, A. Desempenho de cultivares de girassol em duas épocas de plantio de safrinha no Planalto Norte Catarinense. Scientia Agraria, v.9, p.41-48, 2008. DOI: $10.5380 /$ rsa.v9i1.10131.

CARVALHO, C.G.P. de; OLIVEIRA, M.F. de; ARIAS, C.A.A.; CASTIGLIONI, V.B.R.; VIEIRA, O.V.; TOLEDO, J.F.F. de. Categorizing coefficients of variation in sunflower trials. Crop Breeding and Applied Biotechnology, v.3, p.69-76, 2003. DOI: 10.12702/19847033.v03n01a10.

CARVALHO, C.G.P. de; OZAWA, E.K.M.; AMABILE, R.F.; GODINHO, V. de P.C.; GONÇALVES, S.L.; RIBEIRO, J.L.; SEIFERT A.L. Adaptabilidade e estabilidade de genótipos de girassol resistentes a imidazolinonas em cultivos de segunda safra. Revista Brasileira de Ciências Agrárias, v.10, p.17, 2015. DOI: 10.5039/agraria.v10i1a3804.

CARVALHO, H.W.L. de; OLIVEIRA, I.R. de; CARVALHO, C.G.P. de; LIRA, M.A.; FERREIRA, F.M. de B.; TABOSA, J.N.; RODRIGUES, C.S.; CASTRO, C.R.; MENESES, M.C.; SANTOS, M.L. dos. Adaptabilidade e estabilidade de cultivares de girassol no Nordeste brasileiro. Revista Científica Rural, v.14, p.408-417, 2012.

CASTRO, C.; FARIAS, J.R.B. Ecofisiologia do girassol. In: LEITE, R.M.V.B. de; BRIGHENTI, A.M.; CASTRO, C. de (Ed.). Girassol no Brasil. Londrina: Embrapa Soja, 2005. p.163-210.

CRUZ, C.D. GENES: a software package for analysis in experimental statistics and quantitative genetics. Acta Scientiarum. Agronomy, v.35, p.271-276, 2013. DOI: 10.4025/ actasciagron.v35i3.21251.

CRUZ, C.D.; CARNEIRO, P.C.S. Modelos biométricos aplicados ao melhoramento genético. 2.ed. Viçosa: UFV, 2006. 585p.

GRUNVALD, A.K.; CARVALHO, C.G.P. de; OLIVEIRA, A.C.B. de; ANDRADE, C.A. de B. Adaptabilidade e estabilidade de genótipos de girassol no Brasil Central. Pesquisa Agropecuária Brasileira, v.43, p.1483-1493, 2008. DOI: 10.1590/ S0100204X2008001100006.

Pesq. agropec. bras., Brasília, v.51, n.11, p.1806-1812, nov. 2016 DOI: $10.1590 / \mathrm{S} 0100-204 X 2016001100002$ 
GRUNVALD, A.K.; CARVALHO, C.G.P. de; LEITE, R.S.; MANDARINO, J.M.G.; ANDRADE, C.A. de B.; SCAPIM, C.A. Predicting the oil contents in sunflower genotype seeds using nearinfrared reflectance (NIR) spectroscopy. Acta Scientiarum. Agronomy, v.36, p.233-237, 2014b. DOI: 10.4025/actasciagron. v36i2.17677.

GRUNVALD, A.K.; CARVALHO, C.G.P. de; OLIVEIRA, A.C.B. de; PIRES, J.L.F.; CARVALHO, H.W.L. de; OLIVEIRA, I.R. de. Adaptabilidade e estabilidade de híbridos de girassol convencional e alto oleico na Região Sul do Brasil. Revista de Ciências Agrárias, v.57, p.217-223, 2014a. DOI: 10.4322/rca. ao1270.

INMET. INSTITUTO NACIONAL DE METEOROLOGIA. BDMEP - Banco de dados meteorológicos para ensino e pesquisa. Disponível em: <http://www.inmet.gov.br/portal/index. php?r=bdmep/bdmep $>$. Acesso em: 27 mar. 2015.

LEITE, R.M.V.B. de C.; BRIGHENTI, A.M.; CASTRO, C. de. (Ed.). Girassol no Brasil. Londrina: Embrapa Soja, 2005. 613p.

NAGARATHNA, T.K.; SHADAKSHARI, Y.G.; RAMANAPPA, T.M. Molecular analysis of sunflower (Helianthus annuus L.) genotypes for high oleic acid using microsatellite markers. Helia, v.34, p.63-68, 2011. DOI: 10.2298/HEL1155063N.

NOBRE, D.A.C.; REZENDE, J.C.F. de; BRANDÃO JUNIOR, D. da S.; COSTA, C.A. da; MORAIS, D. de L.B. Desempenho agronômico de genótipos de girassol no norte de Minas Gerais. Revista Agro@mbiente Online, v.6, p.140-147, 2012. DOI: 10.18227/19828470ragro.v6i2.781.

NOGUEIRA, A.P.O.; SEDIYAMA, T.; SOUSA, L.B. de; HAMAWAKI, O.T.; CRUZ, C.D.; PEREIRA, D.G.; MATSUO, É.
Análise de trilha e correlações entre caracteres em soja cultivada em duas épocas de semeadura. Bioscience Journal, v.28, p.877$888,2012$.

PACUREANU-JOITA, M.; STANCIU, D.; PETCU, E.; RARANCIUC, S.; SOREGA, I. Sunflower genotypes with high oleic acid content. Romanian Agricultural Research, n.22, p.2326, 2005.

PIMENTEL-GOMES, F. Curso de estatística experimental. 15.ed. Piracicaba: Esalq, 2009. 451p.

PORTO, W.S.; CARVALHO, C.G.P. de; PINTO, R.J.B.; OLIVEIRA, M.F. de; OLIVEIRA, A.C.B. de. Evaluation of sunflower cultivar for central Brazil. Scientia Agricola, v.65, p.139-144, 2008. DOI: 10.1590/S010390162008000200005.

RODRIGUES, D.N.; CABRAL, L. da S.; LIMA, L.R.; ZERVOUDAKIS, J.T.; GALATI, R.L.; OLIVEIRA, A.S. de; COSTA, D.P.B. da; GERON, L.J.V. Desempenho de cordeiros confinados, alimentados com dietas à base de torta de girassol. Pesquisa Agropecuária Brasileira, v.48, p.426-432, 2013. DOI: 10.1590/S0100204X2013000400011.

SANTOS, H.G. dos; JACOMINE, P.K.T.; ANJOS, L.H.C. dos; OLIVEIRA, V.A. de; LUBRERAS, J.F.; COELHO, M.R.; ALMEIDA, J.A. de; CUNHA, T.J.F.; OLIVEIRA, J.B. de. Sistema brasileiro de classificação de solos. 3.ed. rev. e ampl. Brasília: Embrapa, 2013. 353p.

SILVA, A.G. da; MORAES, E.B. de; PIRES, R.; CARVALHO, C.G.P. de; OLIVEIRA, A.C.B. de. Efeitos do espaçamento entre linhas nos caracteres agronômicos de três híbridos de girassol cultivados na safrinha. Pesquisa Agropecuária Tropical, v.39, p.105-110, 2009.

Recebido em 14 de abril de 2016 e aprovado em 29 de julho de 2016 